\title{
Las bases del Derecho Internacional Americano en la obra de Alejandro Álvarez: solidaridad y vida internacional
}

\author{
Juan Ignacio Arias Krause* \\ Mariela Cecilia Avila**
}

\begin{abstract}
RESUMEN
El jurista chileno Alejandro Álvarez Jofré es una figura destacada en el universo jurídico latinoamericano, tanto por su labor práctica como teórica. En este artículo se analizarán dos elementos de esta última como introducción a un pensamiento más amplio, que en todo momento tiene la pretensión de alcanzar el rango de sistema mediante la incorporación de un nuevo método en las Ciencias Jurídicas. Las dos concepciones que se analizarán en este articulo, "Solidaridad" y "Vida internacional", servirán para mostrar, por un lado, la originalidad de su pensamiento, así como también el valor contemporáneo que se desprende de él. Esto redundará en una apertura de lo jurídico hacia la bistoria y la vida social de los pueblos, que determinan cada una de las manifestaciones que realiza el derecho.
\end{abstract}

Alejandro Álvarez; Derecho Internacional Americano; solidaridad; vida internacional

\section{The bases of American International Law in the work of Alejandro Álvarez: solidarity and international life}

\begin{abstract}
The Chilean jurist Alejandro Álvarez Jofré is a prominent figure in the Latin American legal universe, both for his practical and theoretical work. In this article, elements of the latter were analyzed, as an introduction to a broader thought, which at all times aim to achieve the rank
\end{abstract}

* Licenciado en Filosofía, Pontificia Universidad Católica de Valparaíso. Máster en Filosofía de la Historia: Democracia y Orden Mundial, Universidad Autónoma de Madrid. Doctor en Filosofía, Pontificia Universidad Católica de Valparaíso. Académico e investigador del Instituto de Filosofía, Universidad Católica Silva Henríquez. ORCID: https://orcid.org/0000-0001-8985-9732.Correo electrónico: jarias@ucsh.cl.

** Profesora y Licenciada en Filosofía, Universidad Nacional de Cuyo, Mendoza, Argentina. Doctora en Filosofía, Pontificia Universidad Católica de Valparaíso y Paris 8 Saint-Denis. Académica e investigadora de la Escuela de Filosofía, Universidad Católica Silva Henríquez. ORCID: http://orcid.org/0000-0002-93472191. Correo electrónico: mavila@ucsh.cl.

Este trabajo se elaboró en el marco del Proyecto ANID-Fondecyt Iniciación N¹1170812, denominado "Aportes para la construcción de una concepción de eticidad internacional. Una interpretación filosófica de las tesis del jurista Alejandro Álvarez”.

Artículo recibido el 28.10.2019 y aceptado para su publicación el 6.5.2020. 
of system by incorporating a new method in the Legal Sciences. "Solidarity" and "International Life" are two concepts incorporated within his work that will serve to show, on the one hand, the originality of his thought, as well as the contemporary value that emerges from it, which will result in an opening of the legal to the history and social life of the people, which determine each of the manifestations that perform the right.

Alejandro Álvarez; American International Law; solidarity; international life

\section{INTRODUCCIÓN}

$\mathrm{L}$ a figura de Alejandro Álvarez destaca por haber sido en su momento "el más renombrado jurista internacional latinoamericano del siglo $\mathrm{XX}^{\prime \prime} \mathrm{y}$, con ello, por moverse dentro de los círculos internacionalistas más importantes del pasado siglo, no solo de América (donde forma parte, por ejemplo, de la fundación en 1912, junto a James Brown Scott, del Instituto Americano de Derecho Internacional) sino también de Europa (como ejemplo, nuevamente, destaca que en 1919 fuera nombrado miembro de la Corte Permanente de Arbitraje de La Haya; en 1921 fundara el Instituto de Altos Estudios Internacionales de París y en 1946 se convirtiera en juez electo de la Corte Internacional de Justicia).

Junto con ello, la importancia de su pensamiento es remarcada por Karl Strupp, para quien el jurista chileno "había llegado a ser para la América, como Hugo Grocio para la Europa de su tiempo, el padre científico del Derecho Internacional" 2 . Con esto se enfatiza el valor teórico de su doctrina, en cuyo contenido aún se pueden rastrear importantes elementos, que sirven para pensar las complejas fórmulas que han adoptado las políticas mundiales en las últimas décadas, atravesadas por el sello de la globalización, las crisis de la soberanía y las políticas regionales (ya sea en contra o a favor de ellas). En su doctrina, y pese a que la especialidad de su disciplina lo restringiera a los ámbitos jurídicos, Alejandro Álvarez desarrolló una rica y vasta obra que destaca tanto por su calidad como por su amplitud, abierta tanto a la Filosofía como a una Sociología del derecho, áreas con las que establece un fecundo diálogo con el fin de asentar los principios y las bases del método con el que construiría su teoría del Derecho Internacional.

En este artículo se han de acentuar dos elementos tomados de su doctrina, que sirven para demostrar el carácter peculiar de su pensamiento. Primero, se revisará el principio de la solidaridad por él expuesto, que sirve para validar la posición particular del continente americano dentro del universo jurídico, al propio tiempo que propicia un distanciamiento de las teorías individualistas que caracterizaban al continente europeo. En segundo lugar, se revisará una de las nociones que dentro de su teoría tiene mayor alcance tanto a nivel filosófico como jurídico, tal es la concepción de "vida internacional

\footnotetext{
${ }^{1}$ Obregón, 2006, p. 983.

2 Errázuriz, 1958-1960, p. 95.
} 
de los pueblos”, que dentro del sistema del jurista chileno sirve como base para lograr una reconstrucción del Derecho de Gentes ${ }^{3}$.

La intención de analizar estas dos concepciones es la de poder vincular el pensamiento de Álvarez a un universo conceptual más amplio, destacando la originalidad que contiene, fundamentalmente por su carácter situado histórica, social, ética, política y jurídicamente. Esto permitirá también la presentación de un elemento particular que da cuenta de esta originalidad, y uno general, en donde se basa su sistema. Esto último se desarrollará en el siguiente sentido: comenzando de lo particular se irá a lo general, con el fin de mostrar las tesis de Alejandro Álvarez siguiendo su propio método de presentación, que tiene su base en el conjunto de hechos que construyen la conciencia jurídica y moral de las naciones, siendo esta la que constituye la "vida de los pueblos", y puestos en el terreno internacional, ella será una "vida internacional". La historia independiente de América, en opinión del jurista chileno, nació bajo el sello de la solidaridad y es esto lo que determinaría la vida del continente. Desde ya se puede apreciar que el concepto de vida que es utilizado para describir un tipo de relaciones jurídicas, es más amplio que estas y que las comprende. El elemento jurídico es parte de esta vida y, en este sentido, el carácter normativo debe ajustarse a ella, servirle como momento de su exteriorización, en el que aquella vida se presenta objetivada, mas en ningún caso debe restringir lo que le es más propio, su vitalidad.

\section{LA SOLIDARIDAD COMO PRINCIPIO PRÁCTICO}

Luego de ser nombrado profesor de Derecho Civil en la Universidad de Chile en 1895, Alejandro Álvarez continuó sus estudios en la capital francesa, donde en 1897 obtuvo el diploma de la Escuela Libre de Ciencias Políticas de París y, al año siguiente, el grado de Doctor en Derecho por la Universidad de París. Lo interesante de estos datos biográficos ${ }^{4}$ son las fechas, pues apenas 5 años antes de su llegada a la Ciudad Luz, Émile Durkheim había publicado su célebre libro La división del trabajo social (1982), que tuvo como base su tesis doctoral, cuyo nombre original era La solidaridad social. Este libro, decisivo en las ciencias sociales, sostiene su tesis principal a partir del concepto de solidaridad y su desarrollo en las sociedades primitivas. En dichas sociedades la solidaridad se daría de un modo mecánico por la semejanza cultural entre sus miembros, a diferencia de lo que sucede en las sociedades donde el número de integrantes no hace sostenible dicha homogeneidad. Esta diferencia ha provocado también la necesidad de dividir el trabajo para satisfacer las necesidades, dando como resultado, a la vez, la división cultural y de costumbres de quienes componen la sociedad. En este caso, la solidaridad también se ve afectada, pues rompe con los vínculos inmediatos, teniendo que ser reemplazados por un

\footnotetext{
3 Álvarez, 1942.

${ }^{4}$ Para una pormenorizada referencia biográfica y bibliográfica véase MoRALEs, 1958-1960, pp. 8-25.
} 
nuevo tipo de orden que los posibilite de manera mediata. Este segundo caso recibe el nombre de solidaridad orgánica y es propiciada por una normativa, ya sea moral o legal.

Junto con esta referencia fundamental para las Ciencias Sociales hacia fines del siglo XIX, es interesante notar que dentro de la propia tradición política francesa, el concepto de solidaridad ya contaba con una importancia destacada, pues estaba a la base de los movimientos socialistas y reclamando para sí el hecho de ser la heredera de la Fraternidad -uno de los principios fundacionales de la Revolución de $1789^{5}-$. En efecto, como apunta Carlos Miguel Herrera, "el concepto de solidaridad se desplegará con mayor ambición en tiempos de construcción de un orden democrático, en particular como fundamento material de la República"6. Este concepto, dentro del contexto, va adquiriendo una plasticidad social, pues pasa de ser un mero principio moral a convertirse en un fundamento práctico del desarrollo social. Sin embargo, hay que notar que en este tiempo, la solidaridad no tendría la potestad de pasar de ser un principio basal a nivel estatal a un nivel internacional, y esto porque las políticas en este ámbito se encontraban dentro del contexto westfaliano cerrado y encerrado en sus soberanías. La esfera internacional seguía moviéndose bajo el paradigma moderno, el de la lucha de todos contra todos, tal como evidencian las guerras que se sucedieron durante el siglo siguiente ${ }^{7}$.

Es en este contexto que se debe situar la formación, información y novedad del pensamiento de Alejandro Álvarez, y allí destacar el que será uno de los aportes de su teoría del Derecho Internacional: poner a la solidaridad como uno de los principios fundamentales de su sistema y, a la vez, como el elemento que imprimiría un nuevo sello en los estudios del Derecho en materia internacional ${ }^{8}$. La originalidad del jurista, en este sentido, es notoria, pues incluye un elemento que primero en política y luego en las Ciencias Sociales sería cardinal, pero que en el ámbito jurídico internacional no pasaba de ser algo cercano a un ideal de la razón, al modo kantiano. En efecto, aunque la solidaridad cumpliera una función regulativa del pensamiento, no tenía un correlato representativo, y siempre era situada adelante, en un más allá, divino o terreno, con un claro carácter teleológico. De hecho, el planteamiento cosmopolita de Kant en, Sobre la

\footnotetext{
${ }^{5}$ Según Hauke Brunkhorst la solidaridad sería la heredera de dos tradiciones culturales: la judeocristiana de la caridad y la fraternidad revolucionaria, que a la vez propiciaría la solidaridad republicana de cooperación cívica. La primera posición se ajusta a la intención de Pierre Leroux, quien se consideraba el creador de la palabra socialismo, tomada para reemplazar la caridad cristiana, y dotar de un sentido político la colaboración entre los integrantes de una comunidad, para ello dicha solidaridad debería concretarse en la forma de Asociaciones de trabajadores y obreros (véase YAÑEZ, 2018).

${ }^{6}$ Herrera, 2013, p. 64.

${ }^{7}$ No deja de ser interesante que en la década del 20 del siglo XX, Max Weber aún destaque cuatro "situaciones" de solidaridad, excluyendo todo tipo de solidaridad a nivel internacional. Así hablaría de la solidaridad que se da en las "comunidades familiares y de vida" (WEBER, 2014, p. 177) como la casa y el clan (correspondiente a la solidaridad mecánica de Durkheim); las que se dan monopolizadas por la coacción, como acontece, por ejemplo, en las asociaciones políticas (solidaridad orgánica, de Durkheim); las asociaciones que persiguen algún tipo de lucro (2014, p. 178); y en ciertas asociaciones de trabajadores.

${ }^{8}$ La notion de solidarité a ainsi remplacé l'ancienne conception de l'indépendance et de la souveraineté absolue : si jadis on estimait que ces deux attributs étaient indispensables à l'existence de l'Etat, ils ne sont plus actuellement jugés incompatibles avec l'interdépendance réciproque. ÁlvarEZ, 1912, p. 30.
} 
paz perpetua, funciona justamente de esta manera, al modo de un principio regulativo9, y en este sentido, el sistema de una sociedad internacional (la confederación de naciones, propuesta por el filósofo de Königsberg) actuaría de la misma forma.

De este modo, al plantear la solidaridad como un principio del sistema jurídico, así como lo hace Álvarez, nos enfrentamos con el doble problema del principio en toda construcción que pretenda tener una estructura sistemática, tanto en su aspecto formal como material ${ }^{10}$. No obstante, hay un elemento particular en su teoría , y es que desde el comienzo dicho principio no funciona como una forma ideal, sino como un correlato en la realidad. Ciertamente, este principio en su obra no es presentado como un postulado de la razón práctica, cuya finalidad sería que las sociedades alcancen un nivel mayor de perfección, por el contrario, es algo que ya ha existido, que tiene una historia determinada y que se ha desarrollado en conjunto con los pueblos de un continente entero: el americano. De manera que, junto con cumplir con el carácter formal que se le pide a todo principio en una construcción sistemática (esto es, que tenga una cierta pretensión de universalidad aunque esta universalidad tampoco es formal, sino que deberá ser situada, con validez para un tiempo y lugar específico), este principio tiene un fondo material, pues ha sido probado y tomado de la misma realidad. Es un principio, podemos sostener, concreto, no a realizar ni a comprobar, sino que realizado ${ }^{11}$.

Como se dijo, el problema del principio es, tal vez, el primero y principal escollo en toda disciplina que pretenda alcanzar un grado de sistematización, y con el que se tiene que enfrentar. Cada elemento que se desprenda de su formulación debe encontrarse vinculado a él, a la vez que debe ajustarse al principio de no contradicción. Y en

9 Truyol y Serra, 1996.

${ }^{10}$ La pretensión de sistematizar los aspectos internacionales tanto políticos como jurídicos de América en la primera mitad del siglo XX, no era exclusivo de Alejandro Álvarez, de hecho se pueden rastrear proyectos más ambiciosos que el del jurista chileno, empero no más rigurosos. Álvarez se mantiene fiel a la solidaridad como principio metódico (tenga esta su realización en el plano político, cultural, psicológico o jurídico) para organizar su estructura sistémica, en cambio, las diferentes pretensiones se ciñen más a la historia empírica, al hecho cerrado con valor en sí mismo que a un principio específico. Así los intentos de dar cuenta de un sistema internacional americano, funcionan como una recolección de hechos remontables hasta el descubrimiento del Nuevo Continente por parte de Colón (que, de seguir con este esquema hoy, y debido a la cantidad de nueva y valiosa información que se tiene del mundo precolombino, podría seguir remontándose aún más hacia el pasado). Destacamos este intento en el texto publicado en Buenos Aires en 1925 de Lucio Moreno Quintana, El sistema internacional americano.

${ }^{11}$ Interesante de destacar es la Memoria para optar al grado de Licenciado en Ciencias jurídicas y Sociales de la Universidad de Chile de Helmut Brünner de 1938, quien asume el mismo método para escribir acerca de los "Aspectos del sistema internacional americano". Presente está allí la idea de sistema, como se puede observar en el mismo título de la tesis, que debe cumplir con la cualidad formal que se le exigía, como tener un "encadenamiento lógico y de causalidad, que justifique su denominación como tal sistema" (BRÜNNER, 1938 , p. 15). Partiendo de esta necesidad, los elementos que comprenden el sistema, pretendido por el autor, "se desenvuelven y tienen su explicación en la evolución de los hechos, en su fase social, económica, moral y política, que la tesis necesariamente debe tener en cuenta para interpretar cumplidamente sus resultados jurídicos”. (p. 17) Es posible destacar que Alejandro Álvarez es ampliamente citado en esta tesis y que su obra forma parte importante de la bibliografía, cuestión que deja en evidencia el lugar que su trabajo tenía en el universo jurídico de la época. 
este contexto, ha sido la filosofía la que se ha ocupado de formular este problema y, por medio de él, a reformularse a sí misma. De hecho, con tal problema la filosofía sale a la luz, una vez que escinde sus dominios de la dimensión mítica.

No obstante, creemos que el rastreo más importante que se puede hacer sobre el principio, más que hacerlo abarcando la historia completa de la filosofía, alcanza un interés destacado -principalmente en nuestro contexto de análisis- cuando esta como disciplina procura desprenderse de la metafísica. Con este desprendimiento busca alcanzar un estatuto científico, cuestión que acontece con el intento de establecer un método que no solo garantice una correcta elaboración argumentativa, sino evidenciar que el propio principio con el que inicia la filosofía, se ajuste a las condiciones epistemológicas que sustenten la posterior construcción teórica.

Alejandro Álvarez también se inserta dentro de este contexto antimetafísico para desarrollar su sistema, que construye en la forma de una Filosofía del derecho ${ }^{12}$. Ya desde los primeros años de la formación de su sistema internacional americano, critica la tradición del Derecho natural ${ }^{13}$, pues esta pone como fundamento último de su teoría principios ajenos al ser de las cosas. Esta crítica le sirve para validar el método de observación ${ }^{14}$ propio de la época que le toca vivir, fuertemente determinado por el positivismo. El Derecho Internacional, ya no americano, sino universal (dirá pocos años después), deberá contener un "conjunto de Derechos fundamentales”, que deberán ser tomados de ideas morales y no metafísicas ${ }^{15}$.

La puesta de los principios a partir de la razón práctica que hace Álvarez, lo vincula de manera directa con la tradición kantiana del Derecho, pues esta establece las bases de un sistema internacional no fundado ya en un origen antropológico, sino que, asumiéndolo, sobrepone a él la razón moral. En efecto, Immanuel Kant, en la conclusión a la sección que trata sobre el Derecho cosmopolita en La metafísica de las costumbres, señala un elemento de análisis fundamental, que bien puede establecerse como precepto metodológico. Allí el filósofo alemán indica que, "si alguien no puede probar que algo es, puede intentar probar que no es. Pero si no lo consigue de ninguna de ambas formas (cosa que sucede a menudo), puede todavía preguntar si le interesa aceptar (como hipótesis) una cosa u otra" ${ }^{16}$. Esto vale, continúa aclarando Kant, tanto para la teoría como para la práctica: ya sea para explicar un determinado fenómeno, ya sea para alcanzar un fin. En el ámbito práctico (donde se encuentra inserto Kant cuando escribe estas líneas) este fin puede ser "pragmático (un simple fin técnico) o moral: un fin tal que la máxima de

12 Bohdan Halajczuk destaca esta amplitud teórica de Álvarez: “... su criterio de sociólogo y de filósofo llegaría a predominar sobre el jurista, por eminente que este último haya sido” (1970, p. 151).

${ }^{13}$ Las críticas son semejantes a las que la Escuela Historicista le haría al iusnaturalismo, en tanto pone a la base del derecho un principio universal e inmutable, fundamentado en la ley natural. Early publicists assumed as fundamental that international law is universal because it applies to the community of states; and unchangeable because such is natural law, which is the original source from which international law derives its precepts permitting of no variation except in secondary and minor matters. ÁLVAREZ, 1919, p. 1.

\footnotetext{
14 Álvarez, 1910a, p. 6.

15 Álvarez, 1916, p. 197.

${ }^{16}$ Kant, 1993 , p. 194.
} 
proponérselo es un deber" ${ }^{17}$. Lo propuesto, en este segundo aspecto, funciona como un postulado para alcanzar un fin racional con validez universal, que moviliza a actuar. En el ámbito del Derecho cosmopolita esto que la razón se propone es "un veto irrevocable: no debe haber guerra" y el fin a alcanzar mediante este veto es la paz perpetua.

Lo fundamental de estas aclaraciones kantianas es el fondo teórico-práctico que entregan para el análisis de la urgencia de una renovación del Derecho Internacional, cuyo paradigma es la solidaridad entre naciones, a partir de principios jurídicos, y no la concepción individualista del Estado nación, cuyo veto de la razón sea el mencionado por Kant: no debe haber guerra. Esta afirmación no indica que de hecho no haya guerra, debido a que la hay, porque el devenir humano la acepta y porque no se han creado las asociaciones, los mecanismos ni las mediaciones que aseguren una paz, si bien no perpetua, al menos duradera ${ }^{18}$. La referencia que Álvarez hace a Kant no es casual. La idea de solidaridad, como principio, junto con haber sido una realidad de hecho, a posteriori presenta una realidad práctica, que funciona como un ideal de la razón, al modo kantiano, tal como se señaló hace un momento, que busca regular la acción y, por medio de ella, el derecho. Así lo entiende Alejandro Álvarez: "Todas estas nociones deberán, pues, constituir las bases del Derecho Internacional. Aun suponiendo que en vez de realidades fuesen simples ideas, serán ideas de aquellas que, dotadas de fuerza expansiva y enunciadas en la hora oportuna -como es el caso-, podrán regenerar todo un sistema político o jurídico" ${ }^{19}$.

Para Álvarez, la solidaridad en América se ha dado como proceso que ha presentado tres momentos claros en la formación de las Repúblicas Americanas, que ayudaron a su conformación tanto cultural como cívica, política y jurídica. ${ }^{20}$ En este sentido, se puede decir que la fisonomía propia de las naciones americanas se caracteriza por el desarrollo

${ }^{17}$ Kant, 1993, p. 194.

${ }^{18}$ Es posible destacar, además, que uno de los libros más interesantes de Álvarez, donde expone de manera extendida pero en un lenguaje muy claro (pues está pensada más para ser escuchada que leída) es Después de la guerra. Esta obra lleva el mismo título que la serie de conferencias que dio en la Universidad de Buenos Aires en 1941 (esto es, en plena Segunda Guerra Mundial), con motivo del Doctorado Honoris Causa que le diera dicha Universidad. El título está tomado del texto de Kant antes citado, La metafísica de las costumbres, $\$ 58$.

${ }^{19}$ Álvarez, 1916, p. 198. En 1910, Álvarez escribía entusiasta: Les Etats sont au point de vue économique et intellectuel unis par des liens d'interdépendance, de solidarité. Celleci n'est donc pas, comme on le croit, une utopie, mais une réalité qui est maintenant dans la conscience universelle. La vie internationale moderne s'oriente dans ce sens. Álvarez, 1910a, p. 126.

${ }^{20}$ El primer momento estuvo determinado por la conformación y estabilización de la vida política y, en materia internacional, por la creciente preocupación de la defensa de su autonomía, con el fin de no permitir otra dominación externa. Este período estaría determinado por aquello que es conocido como la Doctrina Monroe. Numerosos son los trabajos que Álvarez le dedica a esta doctrina, primero para rescatar su sentido positivo y el valor que tuviera en la formación de la conciencia independiente de las nuevas Repúblicas americanas y el sentido de solidaridad que nacería en este despertar autónomo de sus soberanías y, luego, para distinguir entre este sentido primero y el desarrollo imperialista que tendría posteriormente por parte de EE. UU.

Sucintamente, el discurso de Monroe de 1823 se puede exponer en tres puntos:

“1. Ningún país europeo puede contradecir el derecho adquirido por las naciones del Nuevo Mundo a su independencia y soberanía. 2. Se reconoce el derecho de estas mismas naciones americanas a organizar las formas de gobierno que mejor se adapten a sus intereses sin la intervención de ningún país europeo en 
que tuviera el principio de solidaridad en el siglo XIX, así como se ha visto de manera sucinta en la nota 5 . Es este sello el que ha determinado la vida internacional de estos pueblos, conformando con ello una psicología propia, especial y específica de este lado del mundo. Es, de igual manera, este sello el que se ofrece como un aporte al derecho en materia internacional, pudiendo -o debiendo- configurarse como principio válido, con miras a romper la hegemonía del principio individualista que había regido la vida social de los pueblos, y, por medio de él, el Derecho Internacional tradicional ${ }^{21}$.

\section{LA VIDA INTERNACIONAL DE LOS PUEBLOS}

Debido al contexto expuesto, los medios que utiliza Álvarez para asentar los principios no como un producto abstracto sino con un valor práctico y con una base concreta, se sitúan principalmente mediante la historia diplomática y de las relaciones internacionales, comprendidas no solo como un conjunto de datos, sino elevadas al estadio de ciencia. En este aspecto radica nuevamente un importante aporte al estudio de las Ciencias Jurídicas por parte de Álvarez, ya que contra la idea de establecer una purificación de las formas, se podría decir que, de alguna manera, poco le importa contaminarlas, llenarlas de contenido, con el fin de establecer una ciencia social que se haga eco de las transformaciones sociales

los asuntos relacionados con la regulación interna, y 3. Las naciones europeas tienen prohibido adquirir por ocupación cualquier parte del continente americano”. Álvarez, 1911, pp. 24-25.

Lo que destaca Álvarez del contenido de esta doctrina, es que sería en gran medida bien recibida por los países americanos, pero no porque fuera dictada por Monroe en un año específico, sino porque estos principios ya formaban parte de los movimientos políticos emancipatorios en América Latina, principalmente por "Bolívar (Colombia), Egaña (Chile), del Valle (América Central), etc". (Álvarez, A. El Nuevo Derecho Internacional en sus relaciones con la vida actual de los pueblos. Santiago de Chile: Editorial Jurídica de Chile, 1962, p. 72). Los fines que persiguen los Estados americanos son los mismos expuestos en esta doctrina: asegurar su independencia y lograr una unidad política, para ello el principio de solidaridad tendría una salida política en la idea de una confederación de Estados, defendida incluso desde antes de las Independencias. Por tanto, como sostiene Vicente Cruchaga (1968, pp. 73-75), siguiendo la idea de la defensa conjunta del continente a las condiciones ganadas luego de las Independencias, para Álvarez habría existido la Doctrina Monroe aunque no hubiera existido propiamente el presidente Monroe, por tanto, la defensa a esta doctrina en absoluto va de la mano a un apoyo a las pretensiones imperialistas de EE. UU. sobre América, sino al contenido mismo de ella. Por lo mismo, en el texto de 1911, y en otros textos anteriores, Álvarez defiende la doctrina Monroe, pero critica la hegemonía posible y real de EE.UU.

El segundo período se habría dado desde el último tercio del siglo XIX hasta la primera Conferencia Panamericana en 1889, momento en que las soberanías se consolidan, diluyéndose la idea de la Confederación de Estados una vez que el miedo a una nueva conquista española se hubo perdido.

El tercer período, que va desde la última etapa señalada, hasta el momento que Álvarez habría escrito su libro (véase Álvarez, 1910), se caracteriza por la consolidación del orden interno de cada país, y "por el amor a la paz y el deseo de fortalecer un triple vínculo de interés: con Europa, con los Estados Unidos y entre ellos mismos" (ÁLVAREZ, 1910, p. 20) realizándose en este período un gran número de conferencias y reuniones continentales. Algunas de ellas fueron la $2^{\mathrm{a}}, 3^{\mathrm{a}}$ y $4^{\mathrm{a}}$ Conferencia Panamericana, celebradas entre 1901 y 1910; la Conferencia Centroamericana de la Paz, celebrada en Washington en 1910 y el Congreso Científico Panamericano, celebrado en Chile entre 1908 y 1909.

21 Álvarez, 1962, pp. 222 y ss. 
que habían ocurrido desde el siglo XIX, y que constituyen las formas de presentación de aquello que denomina la "vida internacional de los pueblos".

En 1912, por ejemplo, llamaba a incorporar dentro del estudio jurídico internacional el derecho público, derecho internacional y economía política como "las principales guías de la conducta de los hombres y los destinos de la humanidad"22. Posteriormente, y una vez visto el destino europeo posterior a la Primer Guerra Mundial, abogaría por la necesidad de incorporar al estudio jurídico todos los elementos que se ven involucrados en la "vida social" de los pueblos, como el aspecto político, nacional e internacional, económico, social y psicológico ${ }^{23}$. En este sentido, la teoría de Álvarez se irá enriqueciendo a la luz de los acontecimientos del siglo, haciéndose cargo y siendo fiel a su propio método. Este tiene un fundamento filosófico que diverge completamente del carácter individualista con el que se había desarrollado el Derecho Internacional (en particular, desde la llamada Paz de Westfalia) y con la concepción de los Estados nacionales como individuos que se vinculan entre sí al modo de una sociedad (por tanto, semejante a la sociedad civil, determinados por la guerra de todos contra todos, según la fórmula hobbeseana). Se hace necesario destacar cómo podría operar con el fin de establecer un orden en el desarrollo de esta nueva forma de entender el Derecho Internacional y, al mismo tiempo, para destacar la distancia que toma de la tradición europea.

En este último aspecto, para hablar de las diferencias culturales que producen nuevos tipos de órdenes jurídicos, Alejandro Álvarez utiliza la antigua usanza (cara a Montesquieu y luego a Hegel) de distinguir cada una de sus características con la denominación de genio, llegando a sostener al final de sus días que el genio (o el carácter) de los pueblos es el resultado de su psicología ${ }^{24}$. Así, hablará del genio americano, para distinguirlo del europeo, asiático, etc., y dentro de cada continente, puede hablar del genio anglosajón, germano o eslavo, etc. ${ }^{25}$. La intensión va en la línea de dotar la normativa de cada región con las características que le son propias, teniendo en consideración tanto su geografía como su historia cultural, política y social. Además, es importante hacer notar que Álvarez al utilizar este término, lo que pretende es distinguir claramente la diversidad y, desde ella, la riqueza de cada cultura y lo que le es propio para poder aportar en los distintos órdenes jurídicos.

Ciertamente, y siguiendo a Montesquieu, se encuentra en su intensión precisar estas diversidades cuando distingue los distintos tipos de genios que muestra cada pueblo, y esto se encuentra también presente en Hegel cuando habla del Genius des Volk. Sin embargo, Álvarez se distancia del evidente carácter eurocéntrico que caracteriza sus presentaciones filosóficas, pues lejos se encuentra el jurista americano de ser la tabla de medida de civilidad que distingue entre la superioridad o inferioridad de culturas. Sin embargo, puede apreciarse una clara cercanía entre la teoría de Álvarez y el elemento

\footnotetext{
22 Álvarez, p. 1.

23 Álvarez, 1944, pp. 221 y ss.

24 Álvarez, 1962, p. 150.

25 Álvarez, 1962, p. 150.
} 
“espiritual”, que es destacado por ambos filósofos. En efecto, todos aquellos elementos que coordinados y en mutua relación constituyen la "vida social" de los pueblos (aun no de los Estados) es lo que engloba la concepción de "espíritu" utilizado por los filósofos (recuérdese el texto fundamental de Montesquieu: El espíritu de las leyes; y el momento más alto del entero sistema hegeliano es una Filosofía del espíritu). Esto evidencia que la caracterización de ese nivel de comprensión del desarrollo social solo pueda hacerse de un modo sistemático, pues se mueve en órdenes diversos pero funcionando de manera simultánea en una estructura (política, jurídica, cultural, religiosa y social) determinada.

De esta manera, y con la finalidad de poder expresar en lo objetivo los fenómenos que componen la vida social (y espiritual) de cada pueblo, se requerirá una reelaboración de las bases políticas y jurídicas y, a su vez, de las bases de una disciplina que posibilite esta reestructura, que debe tener en cuenta el origen, el objeto y el contenido del Derecho que lo posibilite. En cuanto el origen, sostiene Álvarez, este se debe encontrar en la “conciencia jurídica” de los pueblos, estrictamente, en la "opinión pública”, la que constituye la vida de los pueblos ${ }^{26}$ (contra la idea, fundamentalmente ligada a la tradición iusnaturalista, de que el Derecho tiene un origen en sí mismo ${ }^{27}$ ). En cuanto al objeto, debe "realizar la solidaridad humana" 28 , y, en cuanto al contenido, y contra el postulado también iusnaturalista que lo presentaba como universal e invariable, se debe conceder valor a la realidad social e histórica de las naciones. En este sentido, dice Álvarez:

En el futuro, los estudios de 'Filosofía del Derecho', 'Ciencia Jurídica', 'Teoría Jeneral del Derecho', i otros similares, deben proponerse no en el estudio del Derecho en sí mismo, en abstracto, sino trazar las grandes líneas de la evolución a la luz de la historia [...] investigar los diversos factores sociales que, desde la segunda mitad de dicho siglo [el XIX], han influido para orientar el Derecho hacia una nueva faz: el Derecho de carácter social. ${ }^{29}$

Con esto, los ejes fundamentales de una posible y futura Filosofía del derecho quedan trazados: esta debe tener su origen en la conciencia jurídica y moral de los pueblos, realizar la solidaridad humana y desarrollar su contenido desde la realidad social e histórica de los pueblos.

De esta manera, ingresamos a un punto capital en la reconstrucción del Derecho, cuya base se encuentre en el concepto de "vida internacional" con el que se procura romper con todo tipo de formulación abstracta como base de los sistemas jurídicos

26 "En la vida internacional, la opinión pública desempeña diferentes funciones: da nacimiento i también deroga las reglas jurídicas; vijila i sanciona su cumplimiento; facilita su interpretación i desarrollo; pone atajo a la política inmoral de los países poderosos; es una de las mejores garantías del cumplimiento de las sentencias arbitrales; aprueba i consagra los actos que se han llevado a cabo en su nombre por la fuerza, i, por último, reclama i orienta las reformas de la vida internacional". Álvarez, 1988, p. 278.

27 Álvarez, 1988, p. 278.

28 Álvarez, 1988, p. 278.

29 Álvarez, 1988, p. 278. 
internacionales y postular un vínculo estrecho entre derecho y política. En esto Álvarez se inclina hacia el lado de aquellos "intereses vitales, que nunca es posible precisar ni definir, como cuando de la existencia o desarrollo del Estado se trata" ${ }^{30}$, siendo precisamente esta imposibilidad de definición (imposibilidad constitutiva en el que se movería la política) el porqué el derecho no puede establecer unas normas universales, con validez para todo tiempo y todo lugar.

El concepto de "vida internacional" es utilizado por Álvarez a lo largo de toda su obra, siendo en su último libro uno de los ejes principales para la presentación de los nuevos desafíos que debe asumir el Derecho Internacional, que tiene el deber de ajustarse a las condiciones actuales que presenta, precisamente, la "vida internacional". En términos generales, con este concepto base de todo su sistema, Álvarez amplía desde abajo el campo jurídico: el derecho, lejos de tener su fuente en sí mismo, la debe tener en esta vida, que extiende sus dominios a todos los ámbitos de la esfera social. De hecho, muchas veces utiliza el término "vida social internacional” para establecer un paralelismo entre la vida social y la vida internacional de los pueblos: ambas deben tener formas de interdependencia, con el fin de salir del régimen individualista que gobernaba -y gobierna- la vida social y la internacional ${ }^{31}$.

Esta exigencia propuesta por Álvarez, tanto a su disciplina como a la necesidad de establecer un vínculo estrecho entre los acontecimientos sociales, históricos y psicológicos en los que se inserta la llamada "vida internacional", van en la línea antes señalada: el Derecho no es comprendido por el jurista chileno como una disciplina desconectada de su acontecer social, sino que forma parte de esta, siendo, más bien, la objetivización de la conciencia moral y jurídica de cada pueblo.

\section{CONCLUSIÓN}

El interés de mostrar los dos elementos base de la obra de Alejandro Álvarez que se han presentado en este artículo (la solidaridad y la vida internacional), es el de señalar dos rasgos distintivos del jurista chileno, a la vez que poner en evidencia la originalidad que en su época supuso, y que se mantiene, en ciertos términos, inclusive hasta hoy.

El olvido en el que se encuentra su obra, más que representar una suerte de fracaso de la misma, se ofrece, a nuestro juicio, como un fracaso del propio Derecho Internacional, sobre todo a nivel americano. Esto dicho sin el afán de hacer política de ficción (de "cómo habría sido el mundo si..."), sino porque, ya sea de manera tangencial o explícita, elementos del pensamiento de Álvarez sirvieron en su momento para diseñar el mapa de los derechos en el que nos encontramos insertos. Esto queda en evidencia de modo particular en las numerosas referencias a él y a su trabajo que se encuentran, por ejemplo, en el "Estudio preparatorio sobre un proyecto de Declaración sobre los Derechos

\footnotetext{
30 Álvarez, 1916, p. 102.

31 Álvarez, 1962, p. 168.
} 
y Deberes de los Estados" de las Naciones Unidad de 1948, que luego daría lugar a la "Declaración sobre los Derechos y Deberes de los Estados", del año siguiente. En este plano, consideramos destacable que la suya fuera una de las primeras voces en llamar a la creación de una Unión Europea apenas acabada la Primera Guerra Mundial, vaticinando que si esto no se lograba, era muy posible recaer en una catástrofe de carácter semejante. Lo que no se puede considerar como un punto a destacar, sin embargo, es que lo dicho para el continente europeo, por Álvarez, tenía más sentido para nuestro continente, y ha sido en este donde su doctrina ha carecido de vigencia, sobre todo, en la segunda mitad del siglo XX. Se podría decir entonces que, si bien en América Álvarez ha sido olvidado, en el Antiguo Continente goza aún de muy buena salud.

$\mathrm{Y}$ en este sentido, mientras que en nuestro contexto el término solidaridad parece ser una palabra que solo se utiliza para aludir a un sentido utópico, curiosamente, en la obra del jurista chileno el término "utopía” no aparece en ninguno de sus textos. Allí, en la obra de Álvarez, la solidaridad lejos se encuentra de estar presente como un elemento ideológico o teleológico, sino que es, para él, una realidad de hecho en el desarrollo republicano de un continente. De ahí la necesidad de establecerla normativamente pues ha surgido de la propia vida de los pueblos americanos, de la historia independiente de sus naciones.

Numerosas fueron las controversias que suscitó el planteamiento en torno a la existencia y posibilidad de que el Derecho tuviese, o no, una variante geográfica y situada. Sin embargo, semejante posición no alcanza a ser más que una reacción intransigente a lo propuesto por Álvarez, ya que la consideración de que un Derecho Internacional contenga elementos americanos no se plantea en términos contrarios a un Derecho Internacional Universal. La presentación de la tesis de un Derecho Internacional determinado por problemas y condiciones propias de una región no estaría exenta de polémicas en su época, teniendo una respuesta enérgica por parte del jurista brasileño Manuel Alvarado de Souza Sa Vianna, quien dos años después de la publicación del libro de Álvarez de 1910, Le Droit International Américain, publicaría un texto con el título explícito: De la non existence d'un Droit international américain (esta disputa tuvo tal importancia que apenas unos años después se publicaría un texto para presentarla ${ }^{32}$ ). En ella, el brasileño le objeta a Álvarez que el Derecho Internacional Americano sea un conjunto de problemas y no de principios, en tanto que el Derecho Internacional es, por el contrario, una disciplina que se basa en principios ${ }^{33}$.

Sin embargo, la antigüedad del momento inicial del problema que se aborda en esta disputa no deja de tener importancia y vigencia, y esto es lo que se ha pretendido visibilizar en el presente artículo: no es la formalidad del principio jurídico el objetado por el jurista chileno (que sea formal es la condición de universalidad), sino el fundamento de este, que tendría una base material puesta en lo extrajurídico ${ }^{34}$, esto es, en

\footnotetext{
32 URIARTE, 1915.

33 Madonado, 2011, p. 42.

${ }^{34}$ Monroy, 2007, p. 297.
} 
el contenido social, político y psicológico de los pueblos ${ }^{35}$. Para finalizar, creemos que con estas ideas, Álvarez no se opone a la universalidad del Derecho Internacional, sino que su lucha va, precisamente, en contra de la intención de predicar con ella la cerrazón de los principios, advirtiendo así el peligro que entraña establecerlos como dogmas ${ }^{36}$, válidos para todo tiempo y lugar.

\section{BiBLIOGRAFÍA}

Álvarez, Alejandro, 1910: La diplomacia de Chile durante la emancipación: y la sociedad internacional Americana. Madrid: Editorial América.

Álvarez, Alejandro, 1910a: Le droit International Américain. Paris: A. Pedone.

Álvarez, Alejandro, 1911: "La doctrine de Monroe a la quatrième Conférence Pan-Américane", Reveu Générale de Droit International Public, vol. 18.

Álvarez, Alejandro, 1912: La codification du droit international. Ses tendances-ses bases. París: A. Pedone.

Álvarez, Alejandro, 1916: El Derecho Internacional del Porvenir. Madrid: Editorial América.

Álvarez, Alejandro, 1919: American Problems in International Law. New York: Baker and Voorhis.

Álvarez, Alejandro, 1942: Después de la Guerra. La vida internacional, social e intelectual. Buenos Aires: Editorial de la Universidad de Buenos Aires.

Álvarez, Alejandro, 1944: La Reconstrucción del Derecho de Gentes. El Nuevo Orden y la Renovación Social. Santiago de Chile: Nascimento.

Álvarez, Alejandro, 1962: El Nuevo Derecho Internacional en sus relaciones con la vida actual de los pueblos. Santiago de Chile: Editorial Jurídica de Chile.

Álvarez, Alejandro, 1988: "Filosofía del derecho del futuro". En Anuario de Filosofía Jurídica y Social, vol. $\mathrm{N}^{\circ} 6$.

BrünNer, Helmut, 1938: Aspectos del sistema internacional americano. Santiago de Chile: S/E.

Cruchaga, Vicente, 1968: La igualdad jurídica de los Estados. Santiago de Chile: Editorial Jurídica de Chile.

Durand, Georgina, 1945: Mis entrevistas. Políticos, artistas y hombres de ciencia de Chile. vol. II. Santiago de Chile: Tegualda.

Durkheim, Émile,1982: La división del trabajo social. Madrid: Akal.

Errázuriz, Jorge, 1958-1960: "Discurso en homenaje", Anales de la Facultad de Derecho Cuarta Época, vol. I (1).

35 "Uno de los postulados del Derecho de Gentes es la Universalidad de todos sus principios y reglas, lo que es inexacto. Algunos principios y muchas materias relativas a este Derecho tienen un aspecto continental que debe tomarse en consideración.

El Nuevo Mundo posee una conciencia, un alma, una mentalidad americana que da origen a principios especiales en el Derecho Internacional. Y esta mentalidad unida a condiciones económicas y geográficas del Continente, crea particularidades que deben ser consideradas.

El conjunto de todas estas materias constituye lo que se denomina el Derecho Internacional Americano. Este derecho no destruye sino que da su verdadera fisonomía al Derecho Internacional Universal”. ÁLvarez, pp. 409-410.

36 Álvarez, 1910a, p. 265. 
Halajczuk, Bohdan, 1970: "La jurisprudencia sociológica ante la sociología del Derecho y la jurisprudencia axiológica en la obra de Alejandro Álvarez”, Revista de estudios políticos, $\mathrm{N}^{\circ} 171-172$.

Herrera, Carlos, 2013: "El concepto de solidaridad y sus problemas político-constitucionales. Una perspectiva iusfilosófica”, Revista de Estudios Sociales, No 46, 63-73.

KANT, Immanuel, 1993: La metafísica de las costumbres. Barcelona: Altaya.

KANT, Immanuel, 1998: Sobre la paz perpetua. Madrid: Tecnos.

KANT, Immanuel, 2001: Ideas para una historia universal en clave cosmopolita. Madrid, Tecnos.

Maldonado, Ingrid, 2011: Alejandro Álvarez. Hito histórico del Derecho Internacional. España: Universidad Internacional de Andalucía.

Monroy, Marco, 2007: Ensayos de teoría constitucional y derecho internacional. Bogotá: Universidad del Rosario.

Morales, Sonia, 1958-1960: “Álvarez y su Obra”. En Anales de la Facultad de Derecho, Cuarta Época, vol. I, N ${ }^{\circ} 1$.

Moreno, Lucio, 1925: El sistema internacional americano. Buenos Aires: Editorial Facultad de Derecho y Ciencias Sociales.

Obregón, Luciana, 2006: "Noted for Dissent: The International Life of Alejandro Álvarez". En Leiden Journal of International Law, $\mathrm{N}^{\circ}$ 19(4).

Sa Vianna, Manoel, 1912: De la non existence d'un Droit international américain. Rio de Janeiro: Figueredo Editor.

Trutol y Serra, Anotnio, 1996: Introducción a Kant. Sobre la paz perpetua. Madrid: Tecnos.

Uriarte, Gregorio, 1915: Problemas de politica internacional americana. A propósito de las doctrinas controvertidas por los doctores Alejandro Álvarez y Sá Vianna, sobre Derecho Internacional Americano. Opiniones autorizadas acerca de ese concepto del derecho, expresadas con motivo de la fundación del Instituto americano de derecho internacional. Buenos Aires: Talleres Gráficos Juan Perrotti.

Weber, Max, 2014: Economía y sociedad. México: Fondo de Cultura Económica.

YAÑEZ, Juan Pablo, 2018: "La solidaridad obrera de Pierre Leroux: una exploración de la fraternidad y la amistad entre la filosofía socialista de Pierre Leroux y los textos de La parole ouvrière", Resonancias, Revista de Filosofía, No 4, 2018. 